\title{
Case Report of a Breast Mass with Three Types of Malignant Tumors-Squamous Cell Carcinoma, Invasive Ductal Carcinoma, and Breast Sarcoma
}

\author{
Chao $\mathrm{Li}^{1,2}$ \\ Hongfei Fang ${ }^{3}$ \\ Hongfeng Lu ${ }^{1,2}$ \\ 'Department of Breast Surgery, Hwa Mei \\ Hospital, University of Chinese Academy \\ of Sciences, Ningbo, Zhejiang, 315000, \\ People's Republic of China; ${ }^{2}$ Ningbo \\ Institute of Life and Health Industry, \\ University of Chinese Academy of \\ Sciences, Ningbo, Zhejiang, 315000, \\ People's Republic of China; ${ }^{3}$ Ningbo \\ Diagnostic Pathology Center, Ningbo, \\ Zhejiang, 3I5000, People's Republic of \\ China
}

\begin{abstract}
Breast malignancy comprises malignant tumors originating from epithelial tissue and breast sarcoma arising from mesodermal tissues. Despite heterogeneity in tumors, most malignant tumors of the breast are composed of a single type of tumor. Here, we report a patient with breast tumor consisting of three different types of malignancies - squamous cell carcinoma, invasive ductal carcinoma, and high-grade breast sarcoma.
\end{abstract}

Keywords: breast malignant tumor, squamous cell carcinoma, invasive ductal carcinoma, breast sarcoma

\section{Introduction}

Breast malignancy is the most common malignancy affecting women worldwide and has high mortality rates. ${ }^{1,2}$ On the basis of the composition of breast tissue, breast cancer can be divided into breast cancer originating from epithelial tissue and breast sarcoma arising from tissues of mesodermal origin. ${ }^{3,4}$ Invasive ductal carcinoma is the most common type of breast cancer, while breast sarcoma is extremely rare, accounting for $<1 \%$ of all breast malignant tumors. ${ }^{5-7}$ Most breast malignant tumors are composed of a single type of tumor, and cases in which two or more types of malignant tumors occur together are rare. ${ }^{8}$ Herein, we report a case of breast malignancy in a patient in whom three types of malignancies, namely squamous cell carcinoma, invasive ductal carcinoma, and high-grade breast sarcoma, occurred together.

\section{Case Presentation}

In August 2018, a 77-year-old woman presented to our Department of Breast Surgery, Hwa Mei Hospital, University of Chinese Academy of Sciences with a right breast mass for 1 year that rapidly enlarged in the past 2 months. The patient did not report a history of benign breast disease or a history of cancer. Physical examination revealed a large tumor (approximately $10 \times 10 \mathrm{~cm}$ ) in her right breast, and the tumor had an exogenous growth with an ulcer in the center measuring $5 \times 5 \mathrm{~cm}$ and covered by a white and yellow exudate (Figure 1). Enlarged lymph nodes were seen in the right axillary region. B ultrasonography uncovered a mass measuring $12.6 \mathrm{~cm}$ in diameter in the lateral quadrant of the right breast with enlarged axillary lymph nodes and was staged as BI-RADS 5 (Figure 2). Right supraclavicular lymph nodes displayed unclear boundary and unclear
Correspondence: Hongfeng Lu Hwa Mei Hospital, University of Chinese Academy of Sciences, 4I Northwest Street, Ningbo, Zhejiang, 315000, People's Republic of China

$\mathrm{Tel}+86$ I3957805698

Email luhongfeng777@I26.com 


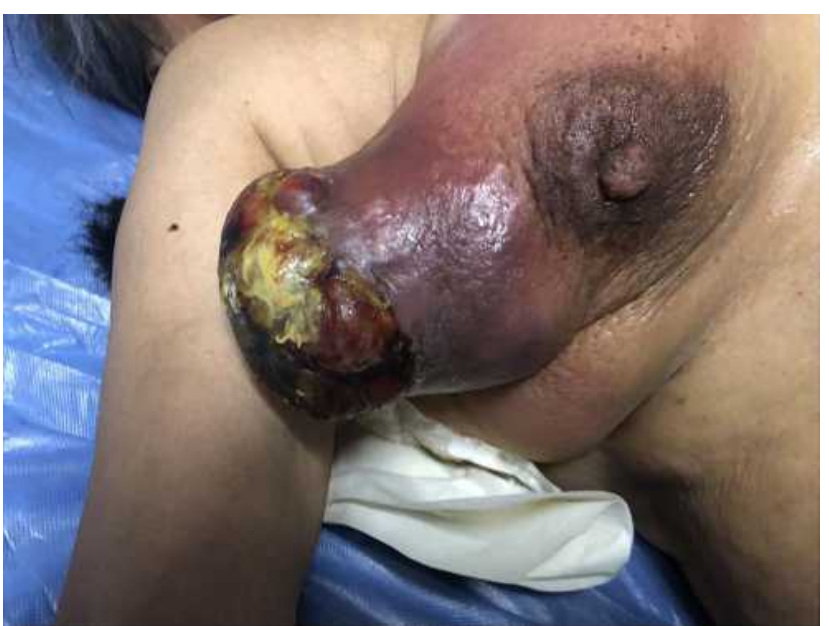

Figure I A large tumor in patient's right breast upon first clinical examination. The tumor had an exogenous growth with an ulcer measuring $5 \times 5 \mathrm{~cm}$ in the center, covered with white and yellow exudate.

structure. The tumor did not invade the left breast and left axillary region. Chest computed tomography (CT) showed two nodules in the upper lobe of the right lung; a large breast tumor with thickened skin; multiple enlarged lymph nodes in the right axillary region; and abnormal bone density on the left third posterior rib, thoracic 2,3 vertebral body (T2, T3), suggesting lung and bone metastasis (Figure 3). Bone emission computed tomography (ECT) scan showed radioactive concentration on the left second and third posterior rib, thoracic 2-4 vertebral body, right inferior scapular angle, left ischium, and bilateral sacroiliac joints. Bone metastasis was suspected. Carcinoembryonic antigen (CEA) was elevated (13.67 $\mu \mathrm{g} / \mathrm{mL}$, normal range: $0-5 \mu \mathrm{g} / \mathrm{mL}$ ) and other tumor markers were within the normal range. No obvious abnormalities were detected in abdominal ultrasound, cardiac ultrasound, brain magnetic resonance imaging, blood routine examination, and hepatic and renal function tests. Mammography was not performed because of size of the tumor and the exuding ulcer in the center. Core needle biopsy was carried out, which showed invasive ductal carcinoma. Immunohistochemistry showed triple negative breast cancer with ER-, PR-, HER2 0, KI-67 15\%, and GATA-3+. The patient was diagnosed with right breast cancer with lymph node, lung, and bone metastasis (T4N1M1). The patient was treated with epirubicin and cyclophosphamide (EC) (E: $90 \mathrm{mg} / \mathrm{m}^{2}, \mathrm{C}: 600 \mathrm{mg} / \mathrm{m}^{2}$ ) every three weeks. After two cycles of chemotherapy, the patient complained of poor quality of life because of the stench emanating from the exuding ulcer and the need to re-dress several times a day. We advised palliative mastectomy to improve her quality of life. Pathological examination showed that the size of the right breast tumor was $13 \times 9 \times 9 \mathrm{~cm}$ and its histological type was metaplastic carcinoma with mesenchymal differentiation. The types of cancer were squamous cell carcinoma and invasive ductal carcinoma. The mesenchymal component comprised highgrade sarcoma with infarction (Figure 4). It was diagnosed based on the morphology of the tumor. The histological grade was grade III. Immunohistochemistry showed: ER-, PR-, HER2(0), Ki-67: 30\%, GATA-3+, CK5/6+, and vimentin $(+)$ which helped confirm a mixture of squamous cell carcinoma, invasive ductal carcinoma, and sarcoma.

\section{Follow-Up}

The patient was put on two cycles of EC followed by six cycles of paclitaxel (P) $\left(80 \mathrm{mg} / \mathrm{m}^{2}\right)$ every week. Unfortunately, the patient could not tolerate the intravenous chemotherapy and was changed to oral chemotherapy
A

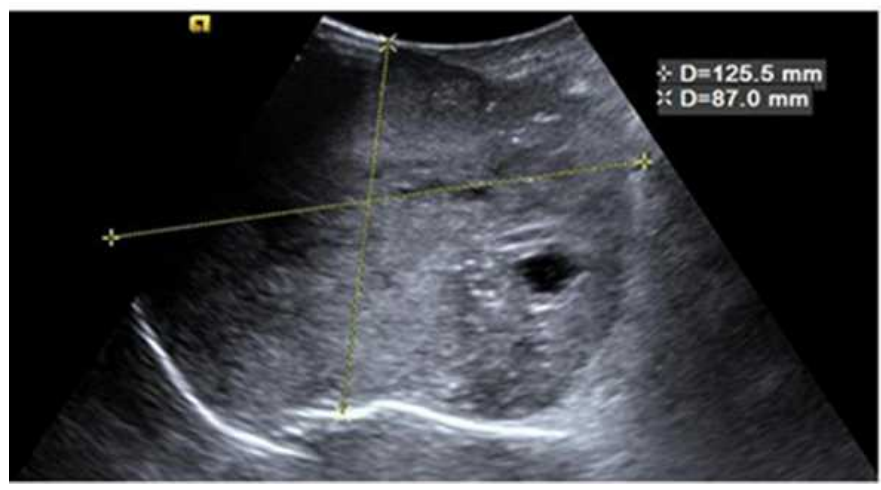

B

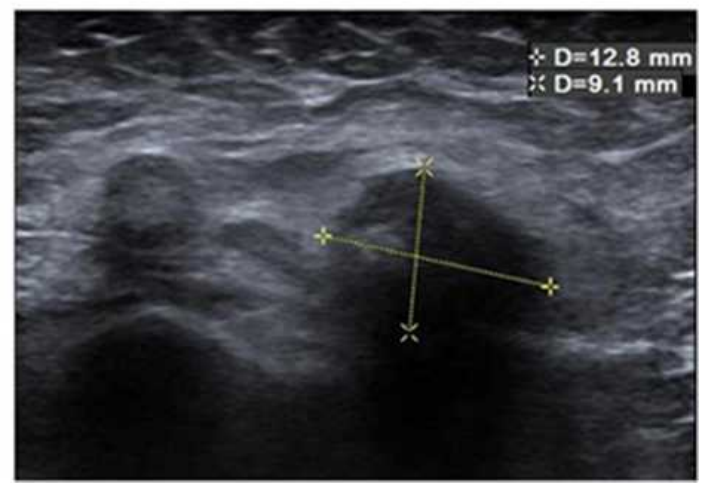

Figure 2 The outcome of breast and axillary B ultrasonography. (A) B ultrasonography showed a I2.5-cm diameter mass in the lateral quadrant of the right breast. (B) B ultrasonography showed enlarged axillary lymph nodes. The larger node had a diameter of $1.2 \mathrm{~cm}$. 
A

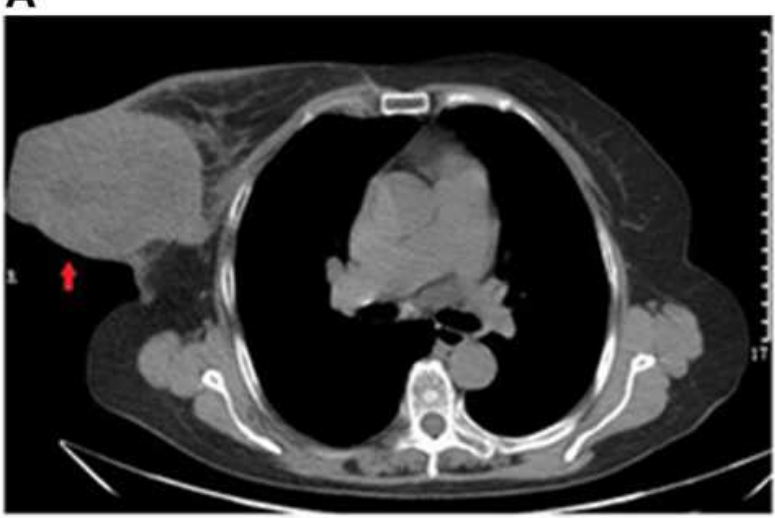

C

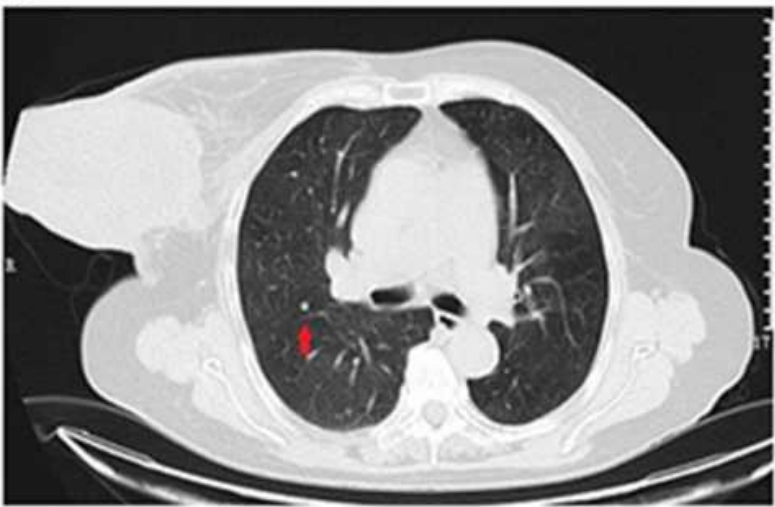

B

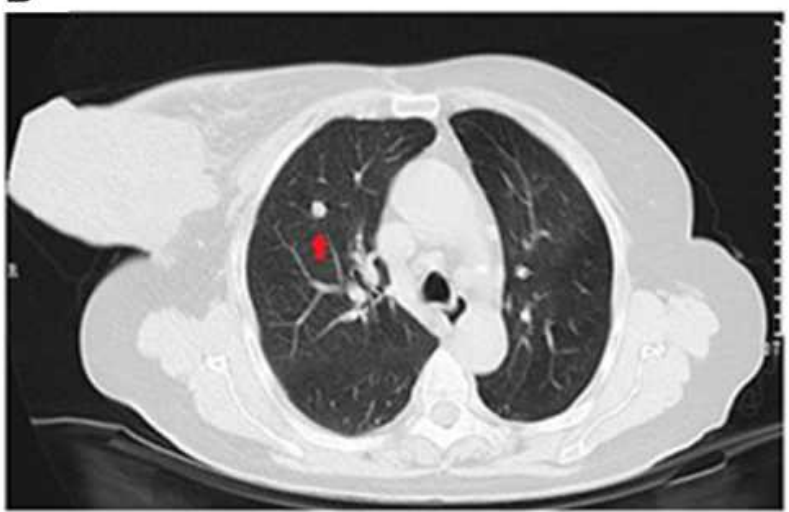

D

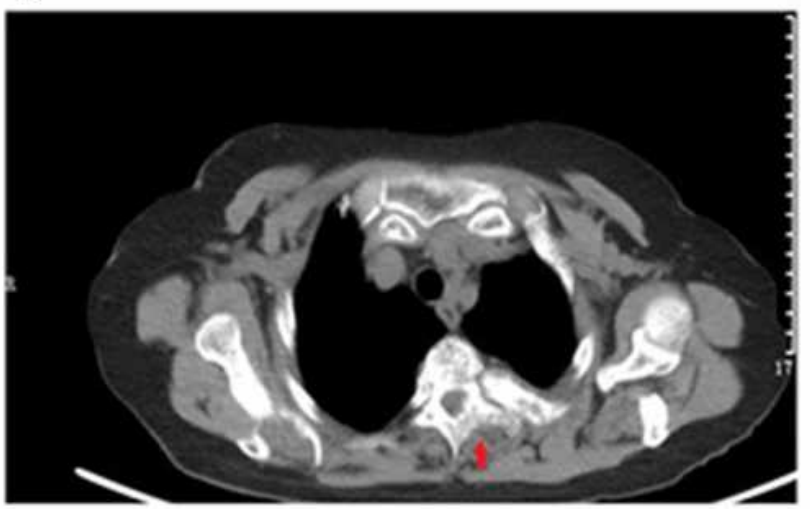

Figure 3 Results of chest computed tomography (CT). (A) The red arrow shows a large breast tumor with thickened skin. (B) The red arrow shows a nodule in the upper lobe of the right lung, indicating lung metastasis. (C) The red arrow shows another nodule in the upper lobe of the right lung, suggesting lung metastasis. (D) The red arrow shows abnormal bone density on the thoracic third vertebral body (T3), indicating bone metastasis.

A

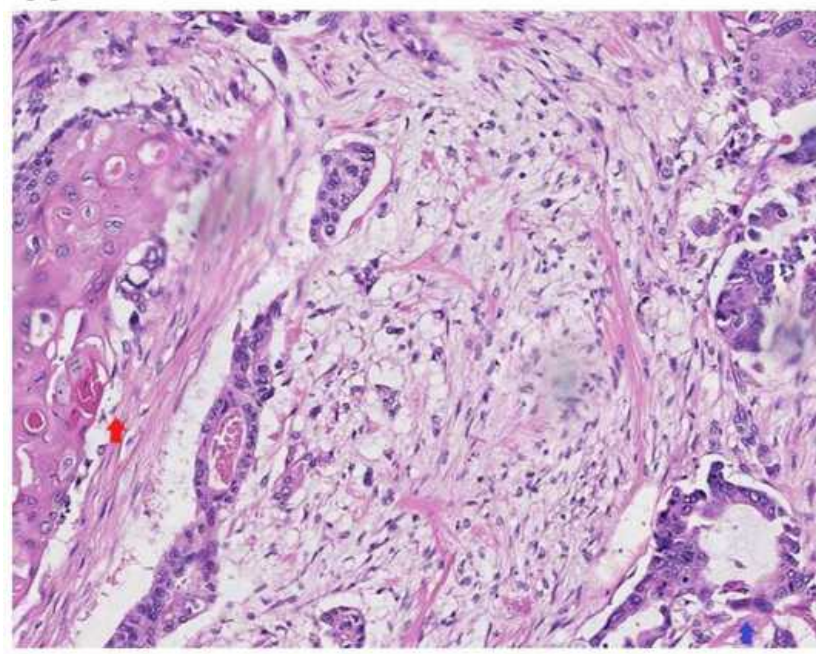

\section{B}

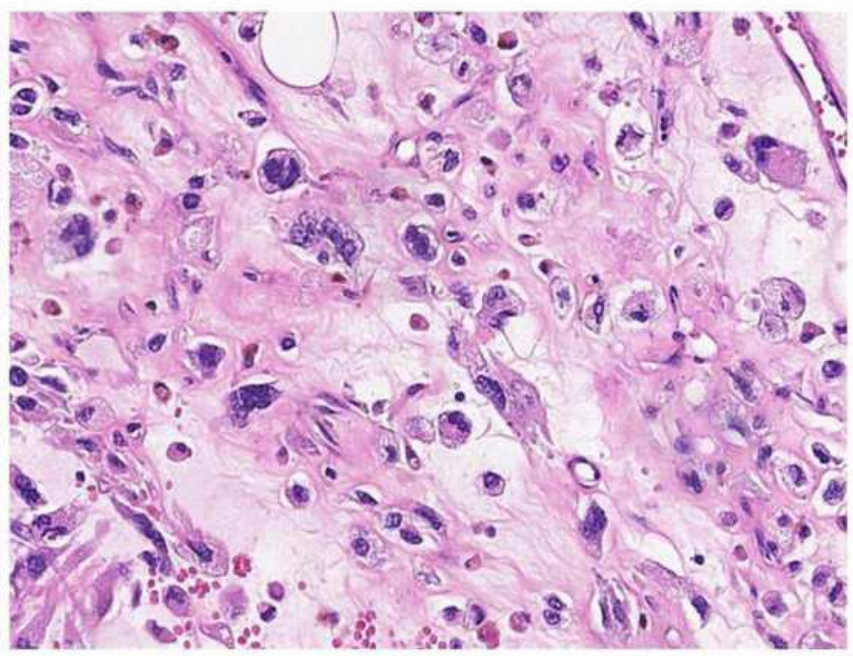

Figure 4 Results of pathological examination. (A) Blue arrow shows invasive ductal carcinoma, while the red arrow shows squamous cell carcinoma. (B) High-grade sarcoma.

of capecitabine $\left(1250 \mathrm{mg} / \mathrm{m}^{2}\right.$ given twice a day from day 1 to day 14) every three weeks after evaluation of stable disease (SD). However, 7 months later, the patient developed lung metastasis. She was treated with nabpaclitaxel and carboplatin (nab-paclitaxel: $100 \mathrm{mg} / \mathrm{m}^{2}$, carboplatin: AUC 2) every week. The patient achieved 
SD for 4 months and discontinued therapy because of the on-going COVID-19 pandemic. A telephonic follow-up revealed that she was alive despite discontinuing all therapy.

\section{Discussion}

In the present report, the patient's breast tumor was composed of squamous cell carcinoma, invasive ductal carcinoma, and breast sarcoma. This is also known as carcinosarcoma, a type of metaplastic carcinoma. Metaplastic carcinoma is an aggressive invasive breast carcinoma, characterized by the dominant component of metaplastic differentiation (squamous, spindle, and mesenchymal). It represents $<1 \%$ of all invasive breast carcinomas. Metaplastic carcinomas can be classified into two subtypes according to the type and amount of metaplastic tissue of the tumor. One was a purely epithelial metaplastic carcinoma and the other was a mixed epithelial and mesenchymal metaplastic carcinoma. Squamous cell carcinoma is seen most frequently in the clinic as metaplastic carcinoma, while mixed epithelial and mesenchymal metaplastic carcinoma is relatively rarely encountered. In mixed epithelial and mesenchymal metaplastic carcinoma, the epithelial component is typically invasive ductal carcinoma. According to mesenchymal differentiation such as chondroid and osseous, mixed epithelial and mesenchymal metaplastic carcinoma get different types. Herein, we reported a rare case of metaplastic carcinoma mixed with squamous cell carcinoma, invasive ductal carcinoma, and sarcomatous components that was diagnosed mainly based on morphology. Immunohistochemistry helped to confirm these diagnoses - metaplastic carcinoma is typically triple negative, squamous cell carcinoma showed CK5/6 positivity, and the sarcomatous component showed vimentin positivity.

The tumor had grown for one year since its first appearance. Therefore, metastasis to the lymph system (axillary lymph node) and circulatory system (lung, bone) occurred. Because of its complex composition, the growth pattern of the tumor differed from that of normal breast tumor. ${ }^{9}$ Physical examination revealed that the tumor underwent exogenous growth with early invasion of the skin and ulcer formation. The tumor grew externally and appeared like a huge vegetative mass adherent on the breast.

Immunohistochemical tests revealed triple negative breast malignancy. The squamous cell carcinoma and invasive ductal carcinoma were treated similarly as triple negative breast cancer. ${ }^{10}$ Chemotherapy based on anthracycline and paclitaxel has been reported to effectively control the disease. ${ }^{11}$ A gene model can be proposed to assess patient prognosis. ${ }^{12}$ Due to the low incidence of breast sarcoma, few large-scale prospective randomized trials have been reported. ${ }^{6}$ Breast sarcoma was treated according to previously reported breast sarcoma cases and the guidelines of soft tissue sarcoma. ${ }^{7}$ Surgery with negative margins and radiotherapy are the main treatments for early stage breast sarcoma., ${ }^{6,7,13-15}$ and the efficacy of adjuvant chemotherapy is still not clear. ${ }^{16-18}$ A meta-analysis conducted in 1997 showed that adjuvant chemotherapy based on doxorubicin and ifosfamide can improve disease-free survival (DFS) but not overall survival (OS) ${ }^{16}$ An update of the meta-analysis including resectable soft tissue sarcomas found that adjuvant chemotherapy improved local recurrence (OR: 0.73, 95\% CI: $0.56-0.94, \mathrm{p}=0.02$ ); distance recurrence (OR: 0.67, 95\% CI: $0.56-0.82, \mathrm{p}=0.0001$ ); and OS (OR: $0.56,95 \% \mathrm{CI}$ : $0.36-0.85, p=0.01)^{17}$ By contrast, analysis of two large clinical trials published by the American Society of Clinical Oncology (ASCO) in 2008 showed that adjuvant chemotherapy does not improve OS. ${ }^{18}$ Chemotherapy can be applied for patients with high histological grade, large tumors $(>5 \mathrm{~cm})$, and with regional nodal involvement. ${ }^{4,6}$ For patients with advanced breast sarcoma, systemic therapy comprising doxorubicin and ifosfamide may be appropriate. $^{7,18}$ In the present case, the patient received both surgery and chemotherapy based on anthracycline and paclitaxel. Although the patient showed good outcomes for about 1 year, the disease progressed. Considering that it was advanced breast disease with a complex composition, the patient achieved good therapeutic effects for a short time, but the long-term prognosis was poor. We believe that our report of a patient with three types of malignant tumors in one breast mass is a clinically rarely encountered entity.

\section{Data Sharing Statement}

The data generated and analyzed during the current case report are not publicly available to protect patient privacy, but can be obtained upon reasonable request from the corresponding author, Dr Hongfeng Lu (email address: luhongfeng777@126.com).

\section{Ethics Approval and Consent to Participate}

Chemotherapy containing epirubicin, cyclophosphamide, capecitabine, nab-paclitaxel, and carboplatin are standard treatments for advanced triple negative breast cancer and 
might be effective for breast sarcoma. Surgery was performed to improve the patient's quality of life. All treatments in this palliative setting were in line with national regulations. We had approval from the ethics committee of Hwa Mei Hospital, University of Chinese Academy of Sciences to publish the case details. The patient provided written informed consent for the publication of her images and case details.

\section{Acknowledgments}

The authors thank members of their department for their assistance.

\section{Funding}

No funding support.

\section{Disclosure}

The authors declare no conflicts of interest.

\section{References}

1. Coughlin SS. Epidemiology of breast cancer in women. Adv Exp Med Biol. 2019;1152:9-29. PMID: 31456177. doi:10.1007/978-3-03020301-6_2.

2. Institute NC. Cancer stat facts: female breast cancer; 2019. Available from: https://seer.cancer.gov/statfacts/html/breast.html. Accessed November 20, 2020.

3. Harbeck N, Gnant M. Breast cancer. Lancet. 2017;389 (10074):1134-1150. PMID: 27865536. doi:10.1016/S0140-6736(16) 31891-8.

4. Vergel JC, Osorio AM, Garcia Mora M, et al. Breast sarcomas: experience of a reference center in Colombia. Cureus. 2019;11(7): e5078. PMID: 31516788; PMCID: PMC6721959. doi:10.7759/cureus. 5078.

5. Dianatinasab M, Fararouei M, Daneshi N, et al. Heterogeneity in risk factors for ductal and lobular breast carcinomas: a case-control study. Int $J$ Cancer. 2019;145(11):2917-2925. PMID: 30719718. doi:10.10 02/ijc. 32182.

6. Makki J. Diversity of breast carcinoma: histological subtypes and clinical relevance. Clin Med Insights Pathol. 2015;8:CPath.S31563. doi: $10.4137 /$ CPath.S31563.
7. Lim SZ, Ong KW, Tan BK, Selvarajan S, Tan PH. Sarcoma of the breast: an update on a rare entity. J Clin Pathol. 2016;69(5):373-381. PMID: 26729013. doi:10.1136/jclinpath-2015-203545.

8. Anderson WF, Rosenberg PS, Prat A, Perou CM, Sherman ME. How many etiological subtypes of breast cancer: two, three, four, or more? J Natl Cancer Inst. 2014;106(8):dju165. PMID: 25118203; PMCID: PMC4148600. doi:10.1093/jnci/dju165.

9. Lahat G, Lev D, Gerstenhaber F, Madewell J, Le-petross H, Pollock RE. Sarcomas of the breast. Expert Rev Anticancer Ther. 2012;12(8):1045-1051. PMID: 23030224. doi:10.1586/era.12.82.

10. González-Martínez S, Pérez-Mies B, Carretero-Barrio I, et al. Molecular features of metaplastic breast carcinoma: an infrequent subtype of triple negative breast carcinoma. Cancers (Basel). 2020;12(7):1832. PMID: 32650408; PMCID: PMC7408634. doi:10.3390/cancers12071832.

11. Puri A, Reddy TP, Patel TA, Chang JC. Metastatic triple-negative breast cancer: established and emerging treatments. Breast J. 2020;26 (9):1793-1796. PMID: 32578306. doi:10.1111/tbj.13946.

12. $\mathrm{Li} \mathrm{C}, \mathrm{Li} \mathrm{X}, \mathrm{Li} \mathrm{G}$, et al. Identification of a prognosis-associated signature associated with energy metabolism in triple-negative breast cancer. Oncol Rep. 2020;44(3):819-837. PMID: 32582991; PMCID: PMC7388543. doi:10.3892/or.2020.7657.

13. Scow JS, Reynolds CA, Degnim AC, Petersen IA, Jakub JW, Boughey JC. Primary and secondary angiosarcoma of the breast: the Mayo Clinic experience. J Surg Oncol. 2010;101(5):401-407. PMID: 20119983. doi:10.1002/jso.21497.

14. Johnstone PA, Pierce LJ, Merino MJ, Yang JC, Epstein AH, DeLaney TF. Primary soft tissue sarcomas of the breast: local-regional control with post-operative radiotherapy. Int $J$ Radiat Oncol Biol Phys. 1993;27(3):671-675. PMID: 8226163. doi:10.1016/ 0360-3016(93)90395-c.

15. Barrow BJ, Janjan NA, Gutman H, et al. Role of radiotherapy in sarcoma of the breast-a retrospective review of the M.D. Anderson experience. Radiother Oncol. 1999;52(2):173-178. PMID: 10577703. doi:10.1016/s0167-8140(99)00070-5.

16. Tierney JF, Stewart LA, Parmar M, Fletcher C, Yang JC. Adjuvant chemotherapy for localised resectable soft-tissue sarcoma of adults: meta-analysis of individual data. Sarcoma Meta-analysis Collaboration. Lancet. 1997;350(9092):1647-1654. PMID: 9400508. doi:10.1016/S0140-6736(97)08165-8

17. Pervaiz N, Colterjohn N, Farrokhyar F, Tozer R, Figueredo A, Ghert M. A systematic meta-analysis of randomized controlled trials of adjuvant chemotherapy for localized resectable soft-tissue sarcoma. Cancer. 2008;113(3):573-581. PMID: 18521899. doi:10.1002/cncr.23592.

18. Le Cesnc A, van Glabbeke M, Woll PJ, et al. The end of adjuvant chemotherapy era with doxorubicin based regimen in resected high-grade soft tissue sarcoma: pooled analysis of the two STBSG-EORTC Phase III clinical trials. J Clin Oncol. 2008;26:559s.

\section{Publish your work in this journal}

OncoTargets and Therapy is an international, peer-reviewed, open access journal focusing on the pathological basis of all cancers, potential targets for therapy and treatment protocols employed to improve the management of cancer patients. The journal also focuses on the impact of management programs and new therapeutic agents and protocols on patient perspectives such as quality of life, adherence and satisfaction. The manuscript management system is completely online and includes a very quick and fair peer-review system, which is all easy to use. Visit http://www.dovepress.com/ testimonials.php to read real quotes from published authors. 